\title{
The promises and pitfalls of polysemic ideas: 'One Health' and antimicrobial resistance policy in Australia and the UK
}

\author{
Adam Hannah $^{1}$ (D) $\cdot$ Erik Baekkeskov $^{2}$ (iD \\ Published online: 29 May 2020 \\ (c) Springer Science+Business Media, LLC, part of Springer Nature 2020
}

\begin{abstract}
Recent scholarship posits that ambiguous ('polysemic') ideas are effective for coalition building between diverse stakeholders: their capacity to be interpreted differently attracts different interests. Hence, in search of political solutions to 'wicked' and similarly complex problems, deploying polysemic ideas would be critical to effective policy-making. This paper scopes the policy-making potential of polysemic ideas by examining the impact of an ambiguous concept known as 'One Health' on responses to antimicrobial resistance (AMR) in Australia and the UK. It offers two primary arguments. Firstly, polysemic ideas can help mobilise broad attention to complex problems: since One Health became associated with AMR, political and administrative attention has grown more intense and coordinated than previously. Secondly, however, a polysemic idea alone may be insufficient to generate effective action: the contrast between Australian and UK AMR policies illustrates that polysemic ideas do not suspend interests, institutions, or ideas that can be readily deployed.
\end{abstract}

Keywords Ideas $\cdot$ Coalition building $\cdot$ Policy change $\cdot$ Antimicrobial resistance $\cdot$ One Health $\cdot$ Health policy $\cdot$ Expertise $\cdot$ Polysemic ideas

\section{Introduction}

How much can conceptual ambiguity help policy-makers when they address difficult public problems? This article focuses on potentials for ideas with a 'polysemic' or 'chameleonic' character to aid in forming and sustaining policy-making coalitions (Smith 2013). That ideas are critical for understanding public policy outcomes is now well established. The

Electronic supplementary material The online version of this article (https://doi.org/10.1007/s1107 7-020-09390-3) contains supplementary material, which is available to authorised users.

Adam Hannah

adam.hannah@uwa.edu.au

Erik Baekkeskov

erik.baekkeskov@unimelb.edu.au

1 School of Social Sciences, The University of Western Australia, Perth, Australia

2 School of Social and Political Sciences, The University of Melbourne, Melbourne, Australia 
literature in recent decades has outlined various types of and roles for ideas at all stages of the policy process. Observing that ideas may mean different things to different people or groups if their meanings are ambiguous ('polysemic'), Béland and Cox (2016) argue that polysemic ideas can pull together actors with different interests or mobilise disengaged interests.

This account of ideas suggests that ambiguous concepts or frames can be crucial in contemporary policy design and development. Public policy-making is described as increasingly complex because public problems are 'wicked' and crises frequent (Head and Alford 2015). Contemporary policy-making combines difficult problems with fragmentation of interests, scientific uncertainty, and decentralised authority. Polysemic ideas may aid policy-making by attracting to coalitions or networks actors who tend to disagree over interests and specific ideas. Such 'big tent' coalitions appear to promise higher likelihood for policy solutions.

The crucial potential for overcoming intractable policy inaction in the face of contemporary policy challenges motivates further study to understand how far polysemic ideas can take policy-making. What follows explores this potential empirically through analysis of a polysemic idea's impact on policy-making in Australia and the UK against a difficult problem. The 'One Health' concept is a polysemic idea par excellence. It has no established meaning beyond the assumption that human, animal, and environmental health are interdependent. Yet from about 2012, it has emerged as the global approach to countering the growing threat of antimicrobial resistance (AMR) (World Health Organization 2015).

Our Australian and UK case analyses first examine whether introducing One Health resulted in diverse stakeholder coalitions for AMR responses. They then investigate whether AMR responses depended on One Health approaches. The cases show that Australian and UK governments both developed strategies against AMR while consulting broad arrays of stakeholders across human and animal health, food production, and the research sector. For AMR responses, the UK has relied on existing centralised institutions for health governance and established economic ideas to generate accountability and initiatives. Australia has mainly relied on its consultative approach while leaving accountability and initiatives to emerge from below the national level. In turn, the UK has arguably made greater progress than Australia in the fight against AMR.

Hence, the case comparison suggests that One Health, on its own, is insufficient for movement towards effective AMR policy. Instead, established governance modes and ideational constructs appear important and necessary for such policy to develop. As such, the analysis qualifies the impact potentials of polysemic ideas. Polysemy can generate broad attention to solving difficult problems by activating and engaging stakeholders. But even mediated by polysemic ideas, paths to policy remain defined by interests, institutions, and specific ideas.

\section{Complex problems, crises, and ideas}

Crises, complex problems, and ideas have long been linked in public policy literature. Peter Hall's (1993) formative work on policy paradigms, for example, suggested that crisis may pave the way for dominant policy paradigms to be usurped by fresh ideas. More recently, ideational scholars have studied cases where paradigm shifts have not followed crises (Carstensen 2017). This has prompted investigation of subtle modes of ideational change, such as interparadigm shifts (Carstensen and Matthijs 2018), ideational path 
dependence (Baekkeskov 2016), and relationships between ideas and forms of power (Parsons 2015). Equally, scholars of 'wicked' problems have studied ideational phenomena, such as framing and discourse (Reinecke and Ansari 2016), learning (Termeer et al. 2015), and evidence uses (Smith 2013). More broadly, change rarely occurs without conceptualised alternatives to the policy status quo or ideational links between 'functional problems' and action (Vis and Van Kersbergen 2013).

Within recent literature linking ideas and complex problems, a particular claim stands out: that 'highly ambiguous and polysemic ideas that mean different things to different people are likely to have broader appeal for coalition builders than better-defined, narrower ideas' (Béland and Cox 2016, p. 432; see also Skogstad and Wilder 2019). Ideas are often central to political coalitions. In the Advocacy Coalition Framework, actors in policy subsystems rally around shared core beliefs (Sabatier 1988). However, such coalitions have generally been seen as stable rather than shifting (although see Nohrstedt 2008). In work on epistemic communities, knowledgeable actors (typically experts) in a field assemble around shared ideas about the nature and causes of problems, and 'a common policy enterprise' related to solving these problems (Dunlop 2013; Haas 1992, p. 3). Similarly, the recent literature has identified various groups that come together around narrow policy elements, such as problem definitions (e.g. 'problem brokers', Knaggård 2015) or policy tools and techniques ('instrument constituencies') (Béland and Howlett 2015; Haelg et al. 2019). However, while these groupings may be transnational, they are most often focused on ideational agreement between similar kinds of actors, rather than forming coalitions between different powerful interests.

Coalition building is probably most valuable where several powerful actors are needed to create effective policies and where costs of inaction are high, but agreements about the existence, characteristics, or causes of problems and solutions are difficult to reach. Given that such challenges can be seen in cases of complex or 'wicked' problems and transboundary crises, polysemic ideas may be particularly important in such situations. Crises convey urgency, uncertainty, and threat to core functions (Ansell et al. 2010). They are extraordinary, can be unexpected, and challenge the legitimacy of dominant ideas and procedures (Boin et al. 2008; Nohrstedt 2008). 'Wicked' problems are generally thought of in terms of complexity and intractability (Rittel and Webber 1973). Although not all crises are complex and not all complex problems will be crises, overlaps are plausible. Complex problems suggest risks of future crisis (climate change being an obvious example). Where potential crises are identified long before their effects appear, political and economic incentives lead actors to discount the future (Levin et al. 2012). Contemporary problems and crises often cross borders, policy sectors, and levels of government, leaving no actor capable of alone responding effectively (Ansell et al. 2010). As such, they can be characterised by uncertainty and fragmentation of authority, and coordination challenges.

In Béland and Cox's (2016) view, polysemic ideas are successful because they allow policy instruments that are potentially divisive on their own to be attached to broader ideas that garner support from diverse stakeholders. It is therefore no coincidence that the 'coalition magnets' they discuss ('solidarity', 'social inclusion', and 'sustainability') deal with poverty, inequality, and environmental protection - three complex and longstanding public policy problems. This argument is also reflected in more recent work emphasising the virtues of more malleable ideas and frames. For example, Skogstad and Wilder (2019) claim that 'multidimensional ideas' not only help create a 'bandwagoning' effect, but also ensure that opposition remains fragmented. Similarly, Faling and Biesbroek (2019) emphasise the importance of employing multiple frames in building cross-sectoral coalitions. 
While claims regarding the power of broader or more ambiguous frames are not unfamiliar in public policy scholarship (e.g. Baekkeskov 2011 on public-private partnership and contracting out; Schmidt and Thatcher 2013 on neoliberalism), this more recent literature highlights potentially significant consequences for attempts to address generally intractable problems: ideas that allow multiple interpretations should not only be seen as links between problem and solution, but also as tools that can help overcome disagreements or mobilise passive actors (Béland and Cox 2016, p. 429).

\section{Unifying stakeholders, guiding action?}

Reiterating the key contention, deploying polysemic ideas can create powerful coalitions by attracting diverse powerful actors. This augments the broadly held view that interest groups presenting a united front are more likely to successfully navigate the policy process (Baumgartner and Jones 1993). There is also reason to examine how far polysemic ideas can drive meaningful action on problems characterised by complexity or potential conflicts of interests and values. Affected stakeholders will often be drawn from several interest and expert communities. Without some means of resolving pre-existing conflicts, a 'big tent' of diverse actors may be little more than a talk shop, with agenda-setting success, but difficulty in policy formulation or decision-making (Howlett et al. 2015). In addition, having opposing interests 'inside' creates opportunities for opponents of some courses of action to exercise veto or obstruct bargaining. Attention from diverse stakeholders is of little value if it does not generate effective coalitions.

Some participants in broad deliberations could be among those contributing to problems. Béland and Cox (2016) describe the example of McDonalds collaborating with the Environment Defense Fund to reduce packaging and waste under the guide of 'sustainability'. But the case is extraordinary rather than representative (Cashore et al. 2019). Absent serious action, outcomes of diverse stakeholder collaborations could resemble what McConnell (2010, p. 228) calls 'placebo policies': superficial action without tackling the underlying problem.

Moreover, as Béland and Cox (2016) describe, McDonalds saved money from the partnership. But in complex problem areas (such as climate change) we do not know whether all coalition members will gain from the effective solutions. Moreover, there is a risk that an emphasis on consensus will lead to avoidance of more intractable issues, in favour of lower hanging fruit (Van de Kerkhof 2006). Indeed, stakeholders may conceivably enter the 'tent' in a bid to co-opt policy-making (O'Toole and Meier 2004).

At the same time, polysemic ideas may predicate themselves on building a broad coalition ('solidarity' - cross-class; 'social inclusion'-cross-class; and as the next section describes, 'One Health' - cross-sector, cross-species). This means that the ideas partly derive their legitimacy from maintaining broad coalitions. Narrowing of actors involved is therefore difficult. Of course, another possibility in relation to complex problems is that there is little need to narrow down the scope of solution sets. Given the multi-sectoral, cross-boundary nature of some complex problems (such as transboundary crises), an array of instruments may need to be employed. Still, the questions remain of what actually is done, who coordinates these efforts, and who is accountable for setting and reaching goals. Solving complex problems may require short-term losses in some places to prevent steeper longer-term pain. And short-term losses may be imposed on actors who do not have prospects for equal or greater long-term gains (i.e. a collective action problem-Olson 1971). 
For government, unavoidably driven by short-term incentives, delaying decisions or avoiding blame may seem much more attractive than dealing with these political difficulties.

\section{One Health and antimicrobial resistance: unity of what?}

To scope the role of polysemic ideas in actual policy-making, we next investigate the political implications of 'One Health', a concept that has become accepted among global and national public health authorities as the key 'approach' to emerging infectious diseases (One Health 2017). Universal recognition of One Health constitutes a political feat in itself, accomplished at least in part through the efforts of entrepreneurial health professionals (Bresalier et al. 2015; Cassidy 2017). One Health is also a polysemic rather than a specific idea. Its core can be stated simply: human, (farm) animal, and (wild) environmental health are interdependent (e.g. World Health Organization 2015, p. VII). That is, diseases cannot be controlled in one sector only, but must be addressed in all sectors. However, different agencies offer different definitions of One Health, which has led some scholars to characterise it as "an "umbrella concept" for a variety of expert perspectives and disciplinary agendas' (Degeling et al. 2017, p. 784). While the need for coordinative action rather than siloing of policy responses is generally recognised, the proverbial devil is in the policy details: What actions? By whom, where, and when? Coordinated by whom? Funded how?

Antimicrobial resistance (AMR) is an emerging crisis that both fits the basic remit of One Health and demonstrates the fundamental challenges in applying it. AMR cannot altogether be prevented because microbial species unavoidably evolve towards immunity to antimicrobial agents (e.g. antibiotics) when these agents are in use. Any policy response will necessarily involve sectors like human and animal medicine, regulators, and food production. Hence, proposed approaches are often multi-sectoral (Laxminarayan et al. 2007; Review on Antimicrobial Resistance 2016; World Health Organization 2011). However, at each stage of specifying actions and policy, polities seeking to adopt and adapt One Health to the AMR challenge face choices with potentially significant costs (Roca et al. 2015; Walsh 2018). For instance, contemporary food production is often dependent on antibiotics; eliminating antibiotics can thus threaten farming outputs and raise the prospect of higher food prices. Similarly, choices may present more opportunities for some actors than others. For instance, pharmaceutical developers can benefit from policies that boost government subsidies for developing new antimicrobials, while limits on antimicrobial uses may threaten their revenues. Specifying the multi-sectoral and multi-jurisdictional AMR policies and actions that follow from One Health thus has the potential to become intensely contested. Moreover, if 'losers' can exercise a veto, then the potential for political settlements on specific policies against problems such as AMR becomes more limited.

\section{Policy-making context: One Health and escalating AMR response}

Although described as an emerging crisis, AMR is an old problem. ${ }^{1}$ AMR has received several waves of global and domestic policy attention, beginning in the 1950s (Podolsky 2018). At the same time, the current wave of attention to AMR both has been closely

${ }^{1}$ More classically named 'antibiotic resistance' (ABR) rather than 'antimicrobial resistance' (AMR). 
associated with One Health and has led to more sustained attention than in previous eras. One Health and renewed problematisation of AMR arose separately, but in parallel in the new millennium (Gibbs 2014; Kahn et al. 2009; Lee and Brumme 2013; Podolsky 2018). AMR captured policy-makers' attention around 2000. During the mid-2000s, other public health issues such as pandemic influenza competed for political attention (Chien 2013). AMR then returned to political agendas with greater force in the years after 2010. Using the WHO as an example, the organisation has made varying levels of effort against AMR in recent decades. To illustrate, mentions of AMR in WHO publications peaked between 1999 and 2004, declined between 2006 and 2009, and increased during 2010-2018 to higher levels than in preceding years (see Online Appendix 1).

The match of AMR and One Health happened during this recent period of renewed political attention to AMR. In 2011, the World Health Organization (WHO) released a six point 'policy package' to guide national-level AMR policy-making with no mention of One Health (World Health Organization 2011). The first WHO document on AMR that mentioned One Health was published in 2013 (Online Appendix 1). Just 2 years later, the WHO's core guidance on AMR policy, the Global Action Plan (GAP), was framed explicitly as part of a 'One Health approach' (World Health Organization 2015: vii). World leaders meeting in the UN General Assembly (UNGA) on 22 September 2016 made a Political Declaration on AMR stating that 'without an effective One Health approach', AMR is likely to have 'massive social, economic and global public health repercussions' (United Nations General Assembly 2016). Hence, within a few short years, the One Health approach had become the guiding frame for global response to the AMR problem.

The recent political attention to AMR appears to have spurred significant response action. The WHO's 2015 GAP (and similar guidance from the UN agencies for animal health and agriculture) and the 2016 UNGA declaration called on countries around the world to articulate National Action Plans (NAPs) for dealing with AMR. Since 2016, the number of NAPs has increased rapidly. From a handful with NAPs in 2016, 93 of the WHO's 164 Member States had developed NAPs by 2018 (Food and Agriculture Organization of the United Nations et al. 2018, p. 7).

However, to understand the role of One Health as a polysemic idea, we must examine two elements of its role in shaping responses to AMR: firstly, whether it has helped to generate response coalitions and secondly, whether government responses to AMR have made greater headway than they might have in the absence of the One Health idea, for instance, by mobilising multiple sectors to act or progressing response across all sectors that contribute to the AMR problem. ${ }^{2}$

The next section analyses One Health's role in AMR policy-making by comparing recent developments in Australia and the UK. Both countries have long had relatively highly developed regulation of antibiotic use and other contributors to AMR in their health and food production systems. However, in the current wave, the UK was among the first to take renewed action (indeed, by some accounts it spurred the renewed drive; Podolsky 2018), and with One Health as just one among several ideas used. In contrast, Australia's new AMR strategy was developed one or 2 years later and explicitly framed by the One Health perspective. As such, while there are no available cases in which One Health is absent from recent AMR policy-making, comparison of these two cases allows

\footnotetext{
${ }^{2}$ We focus on progress rather than effectiveness because AMR remains on the rise. As such, now is too soon to tell whether an 'effective One Health approach' has been realised at any level of governance.
} 
an opportunity to consider what work it did in these countries' AMR policy processes. The case analyses assess whether the following two expectations are fulfilled:

1. Introducing the One Health idea rallied stakeholders to support AMR response.

2. One Health made effective AMR policy more likely.

\section{Assessment 1: Has One Health generated coalitions for AMR response?}

While many actors have been consulted on and tasked with AMR response in both Australia and the UK, the available evidence on these processes suggests resolving AMR has been more strongly associated with the idea of One Health in Australia than in the UK. ${ }^{3}$

In Australia, the national government held a One Health Antimicrobial Resistance Colloquium in July 2013 with the explicit purpose of informing the national AMR strategy (Australian Commission on Quality and Safety in Health Care 2013). This meeting brought together 60 participants from a wide cross section of stakeholder groups. Development of Australia's implementation plan was informed by a National AMR Stakeholder Forum held in November 2015. Approximately 170 stakeholder representatives attended (Department of Health and Department of Agriculture and Water Resources 2017, p. 29). In the UK, consultation on the national strategy took the form of 'technical engagement exercise' in 2012, with 140 stakeholders (Department of Health and Department of Environment, Food \& Rural Affairs 2013, pp. 32-33). The department sought feedback on its initial draft of the strategy. As such, both governments called on a wide range of sectors and stakeholders as they developed plans to address AMR nationally. Calling on many kinds of stakeholders is consistent with the One Health approach. Many stakeholders heeding both calls is consistent with One Health functioning as an AMR attention 'magnet'. Notably, governments called on stakeholders to assemble, rather than stakeholders coalescing spontaneously around their common interest in stopping AMR. The stakeholders might have heeded calls to consultation simply due to their government's authority rather than One Health's persuasive appeal.

In turn, while calling on many stakeholders was consistent with a One Health approach, the two governments' motivations for action against AMR appear differently linked to One Health. The UK's published strategy against AMR mentions One Health five times, in the context of a broad need for collaboration rather than linked to specific initiatives (Department of Health and Department of Environment, Food \& Rural Affairs 2013, p. 4). Australia's published strategy is a document of very similar length and content to the UK's (Department of Health and Department of Agriculture 2015). It mentions One Health twenty times, particularly in relation to specific initiatives on public and professional awareness and disease surveillance.

The UK's AMR strategy describes government's role as 'leadership, stewardship and strategic direction... by holding national bodies to account and ensuring different parts of the system work properly together' (Department of Health and Department of Environment, Food \& Rural Affairs 2013, p. 13). It also assigns all proposed actions to a government department or agency (UK Government 2014). This implies that the UK tackles

\footnotetext{
${ }^{3}$ While the UK has a national strategy, in some cases responsibility is devolved Northern Ireland, Scotland, and Wales, often with unclear approaches to coordination between them. In such cases, the analysis focuses on English policy.
} 
AMR through central leadership coupled with agency and departmental accountability. One Health in the form of horizontal collaboration between sectors is absent from this strategy.

Australia's AMR strategy emphasises multi-sectoral collaboration and One Health in each of its seven priority areas. In turn, Australia's report on implementation categorises 39 separate actions in relationship to One Health. The Australian approach has emphasised communication, delegation, and consensus on AMR. From the outset of planning for the 2015 national AMR strategy, the Australian process aimed to be 'cooperative and designed to benefit all parties' (Australian Commission on Quality and Safety in Health Care 2013, p. 3), with the One Health approach to action providing 'an opportunity to find common ground across sectors' (Australian Commission on Quality and Safety in Health Care 2013, p. 36). In turn, 173 of the 237 actions listed in the implementation plan are delegated to bodies that are not Federal Government departments or agencies (Department of Health and Department of Agriculture 2016). Congruent with the mutual interdependency inherent to the One Health concept, distributed initiative and voluntary collaboration appears to be how Australia manages AMR response.

This evidence on AMR strategy development and implementation is broadly consistent with the first contention about polysemic ideas, which is that they are capable of rallying otherwise contending interests to agree on a public problem. Both governments rallied numerous stakeholders to planning consultations. Notably, governments were central in both cases. In turn, Australia's AMR strategy asked for action from non-governmental actors, with few explicit accountability mechanisms or central controls on who did what. In contrast, the UK's AMR strategy suggests that embracing One Health was not essential in creating AMR response. Rather, the UK's strategy largely articulated AMR response as a multi-sectoral, but centralised endeavour that bears easy similarity to standard UK governance.

We return to the meaning of these differences in the discussion section below, after considering the impact of One Health on the contents of policy responses in more detail.

\section{Assessment 2: To what extent have AMR responses by Australia and the UK depended on a One Health approach?}

Close examination of the national strategies and subsequent achievements suggests that 'big tents' associated with wide consultation have resulted in more than talk. Australian and UK implementation plans for the AMR strategies outline hundreds of actions, in many cases involving collaboration between government and various stakeholders (Department of Health and Department of Agriculture 2016; UK Government 2014). Responses developed during the current, One Health-linked wave of attention to AMR are also more extensive than responses that emerged during the early 2000s (Department of Health 2000; Joint Expert Advisory Committee on Antibiotic Resistance 1999).

According to annual self-assessment surveys ${ }^{4}$ of countries conducted by UN agencies starting in 2016-2017, 19 countries including Australia and the UK have developed AMR NAPs in line with the 2015 Global Action Plan and adopted integrated, multi-sectoral approaches to implementation. The UN surveys allow systematic comparison of Australian

${ }^{4}$ Available at https://amrcountryprogress.org/. 
and UK responses across six major categories (public and professional awareness; education and training; stewardship ${ }^{5}$; infection prevention and control (IPC); surveillance of AM usage; and surveillance of AM resistance). In turn, response scores in these categories range from no action (1) to highly developed activity (5) (see Online Appendix 2). These self-reported data yield indications about national AMR responses. Both countries report considerably more activity in human health than in veterinary health and agriculture. To realise a One Health approach, both would need considerably more intersectoral coordination. However, the UK has reported higher scores than Australia across four of the six areas, slightly more similar policy scores between sectors, and higher average scores for each of the three sectors. This indicates a more advanced and coordinated response to AMR than Australia has achieved.

As previously described, UK AMR strategy relies less than the Australian on the One Health framing. This potentially sets our expectation that polysemic ideas ease policy-making at odds with actual responses. However, the gap between human health and other sectors is also variable across areas. In the UK, the largest gaps in response scores between sectors are in awareness and IPC, while the Australian responses indicate substantial gaps in the development of integrated surveillance programmes.

Qualitative analysis of national implementation reports generally confirms the broad patterns indicated by the UN surveys (see Online Appendix). Both countries have implemented an array of actions, particularly in human health. To promote more appropriate uses of antimicrobials, they run nationwide AMR awareness campaigns targeted at healthcare providers and the public. Both have also updated accreditation standards, educational materials, and curricula for healthcare providers (Australian Commission on Safety and Quality in Health Care 2017; Department of Health and Department of Agriculture and Water Resources 2017, p. 7; Department of Health 2015; UK Government 2014, p. 32). Finally, both countries have developed prescribing tools and guidelines (Australian Government Dept of Health and Dept of Agriculture 2016, p. 27).

AMR response has also taken different qualitative turns in the two countries. In several areas of human health, the UK has taken more initiatives than Australia. These include provision of detailed localised data on prescribing and resistance to health providers, monitoring of public awareness, and the use of financial incentives for providers to make improvements to practice. In turn, Australia appears to have placed more emphasis on coordination between sectors in relation to awareness and IPC, including across human and animal sectors through the Commission on Quality and Safety in Health Care, and the Australian government's 'One Health AMR' website that provides information for consumers, food producers, and health professionals.

A significant area of difference between the countries is sectoral levels of AMR surveillance. Both countries have AMR surveillance systems for human health with regular reporting. But the UK has more developed surveillance than Australia in the other sectors. Through a mandatory EU programme and monitoring by its own Animal and Plant Health Authority, the UK has comprehensive surveillance of resistance in animals and collects data on sales of antimicrobials for animals (Public Health England 2015). This has enabled a cross-sector 'Targets Task Force' to establish voluntary usage targets for food producers (UK Government 2019, pp. 18-19). In contrast, Australia has lagged in animal health surveillance. Progress has stopped at development proof-of-concept surveillance

${ }^{5}$ Stewardship refers to practices that promote the appropriate use of antimicrobials. 
programmes with industry bodies like Meat and Livestock Australia. Hence, as of a 2017 progress report, Australia describes integrated One Health surveillance as a 'long-term goal' (Department of Health and Department of Agriculture and Water Resources 2017, p. 15).

\section{R\&D and international engagement}

Comprehensive AMR also include research and development, and international engagement (these are not measured by the UN survey). Comparison of national implementation documentation indicates that the UK has placed more emphasis than Australia on funding research towards new drugs, therapeutics, and diagnostics, and on the need for international action.

In its 2019-2024 AMR strategy, the UK government claims to have 'invested more than $£ 360$ million in research and development on AMR' since 2014, through various channels, including the UK Global AMR Innovation Fund and the UK-China AMR Innovation Collaboration (UK Government 2019, p. 72). The UK has also supported AMR surveillance in lower- and middle-income countries, by contributing $£ 265$ million to a private foundation (UK Government 2016, p. 10). In 2016, it hosted a global leaders event on One Health and AMR (UK AMR Strategy High Level Steering Group 2017, p. 30). Moreover, its 2014 implementation strategy nominated a UN political declaration on AMR as a national aim, and the UK's Chief Medical Officer was a crucial advocate for renewed global action (Podolsky 2018).

Australia has not contributed resources to $R \& D$ or international initiatives at the same scale, even when adjusting for its relatively smaller economy. The 2017 Progress Review (Department of Health and Department of Agriculture and Water Resources 2017, p. 24) notes that it has funded 90 million AUD worth of research into various aspects of AMR, and states that it 'remain[s] open to contributing to new research initiatives'. However, aside from contributing $\$ 30$ million through three product development partnerships, largely focused on tuberculosis and malaria in the Asia-Pacific region, there is little evidence of concrete action (Department of Health and Department of Agriculture and Water Resources 2017, p. 24).

\section{Discussion: the role of One Health in Australian and UK AMR responses}

One Health has clearly influenced current AMR-related policy-making. The match-up of AMR and One Health after 2010, growing global policy attention to AMR in the same period, and escalating national AMR initiatives in the wake of the 2015 GAP and 2016 UNGA statement collectively support that deployment of polysemic ideas can be associated with more policy-making on complex problems. In addition, Australia and the UK both appear to have attempted coordinated, multi-sectoral approaches to the AMR challenge, consistent with the One Health idea. Moreover, development of policy is still ongoing. As such-where responding to a problem requires diverse coalitions-the analysis suggests that framing responses around an attractive polysemic concept can help draw actors together in initial deliberative stages of policy formulation.

However, the comparison of AMR policy-making in Australia and the UK suggests limitations on the reach of One Health. The UK and Australia have taken different interpretations of government's part in AMR response. The UK government appears to use 
centralised governance with delegation to and reporting back by multiple departments. Australia's government seems to merely convene stakeholders while leaving initiatives, action, and even much of the reporting to local or private actors. In turn, as described, indications are that UK responses to AMR have been more extensive and integrated across sectors than Australian. We are not suggesting that AMR policy-making in either case has been a failure. However, a fundamental claim of One Health activism is that rethinking established (siloed) modes of policy is critical for success. As such, asymmetries, particularly those in the Australian case, given the relatively stronger emphasis on the One Health concept observed there, allow us to identify some of the limits of a polysemic framing.

The contrasts between the cases first suggest that institutional context may have so far been more important to AMR response than the One Health idea. The integrated nature of the UK's National Health Service lends strong government direction to UK health governance, and the UK reports making particularly strong progress against AMR in the human health sector. While Australia also reports making reasonable progress against AMR in human health, it faces institutional barriers to intersectoral coordination that are largely unrelated to One Health. These include a mixed public-private hospital system, the authority and funding of which are also divided between the national and state governments (Duckett 2007). The presence of such divisions of authority align well with Australia's general approach to AMR, which is to define government's role as 'working with stakeholders' and forming 'new partnerships' (Department of Health and Department of Agriculture 2015, p. 6), and its emphasis on specific actions in this domain, such as the development of a 'One Health AMR website', ${ }^{6}$ which is mentioned repeatedly in strategic and review documents.

AMR responses' dependency on such institutional factors is made more plausible by looking closely at surveillance programmes. Surveillance of antimicrobial drug use and resistance are fundamental components of an effective response. Without understanding how medicine is used and patterns of resistance, programmes to improve stewardship and applications of such agents are inhibited. Yet, as already discussed, in Australia the most obvious disparity between sectors is in its surveillance programmes. Progress has been much slower in animal health and food production than in human health despite the strong presence of One Health discourse in discussion of the need for comprehensive surveillance. In contrast, the UK's success with regard to surveillance is partly due to its participation in European Union (EU) programmes that predate the conceptual pairing of AMR and One Health (Department of Health and Department of Environment, Food \& Rural Affairs 2013, p. 20).

The uneven Australian surveillance system may also speak to our contention that diverse coalitions can hinder certain initiatives because some resist policy change to protect their interests. For example, in submissions to a 2013 Senate hearing on Australia's response to AMR, the Australian Chicken Meat Federation and Animal Health Australia emphasised that surveillance should be conducted only in proportion to risk, with the Chicken Federation suggesting that surveillance every 5 years would be sufficient (Finance and Public Administration References Committee 2013, p. 42). Maintaining a high engagement process that emphasises stakeholder consent seems likely to help stakeholders (in this case Australia's meat industry) protect their interests more than leaving government to mandate changes (such as more AMR surveillance).

6 www.amr.gov.au. 
Finally, the case analyses also suggest something of a paradox regarding polysemic ideas. In the academic literature, One Health is often presented as an interdisciplinary paradigm or unifying frame that can be applied to various global health, environmental, social, and economic issues (Kingsley and Taylor 2017). However, in policy-making terms it is usually construed more narrowly as an appeal to multi-sectoral collaboration among professional stakeholders. This can be observed, for example, even in the way in which international progress on AMR is measured (exemplified previously). Yet, multi-sectoralism alone cannot solve AMR, nor are useful responses to AMR necessarily multi-sectoral.

When One Health and AMR were initially paired, UK policy-makers had already hit upon a clear problem framing, what Wernli et al. (2017) call 'AMR as an innovation issue'. Rather than linking AMR to poor coordination between sectors, AMR is often described as a 'market failure' linked to slowing development of new antimicrobials by pharmaceutical and chemicals businesses. Key UK government documents on AMR, including the Chief Medical Officer's 2011 annual report and the 2013 national strategy, discuss not only the 'economic burden' of AMR, but also economic opportunities in new diagnostics and therapeutics (Davies 2013; Department of Health and Department of Environment, Food \& Rural Affairs 2013). Moreover, in 2014 British Prime Minister David Cameron commissioned economist Jim O'Neill to conduct a review of AMR. The terms of reference for the review were cast in explicitly economic language, asking it to (Terms of reference, n.d.):

Examine and boost awareness of the economic issues surrounding the development, spread and containment of antimicrobial resistance (AMR), with a particular focus on...research and development of new antimicrobial drugs.

In contrast, equivalent Australian documents mention only that the problem has economic 'dimensions', and relegate economic impact analyses to the future (Australian Commission on Quality and Safety in Health Care 2013, p. x; Department of Health and Department of Agriculture 2015, p. 32). This difference aligns with the previously described disparity between UK and Australian efforts on AMR-related R\&D and international engagement.

One Health can work with other ideas. Some academic literature on One Health takes economic dimensions of problems and responses into account (see Mackenzie et al. 2013). However, an approach like the UK's would be inconsistent with the Australian government's role in advancing a 'One Health solution' by coordinating stakeholders, rather than direct intervention to correct market failure. Like the plausible importance of each institutional context, the contrast between economic ideas illustrates that One Health on its own offers little actionable guidance for AMR response. Supplementing the polysemic idea with more specific problem and solution framings may therefore provide pathways to action.

\section{Conclusion}

Contemporary discussions of public policy are often characterised by frustration with the difficulties that complex problems and emerging crises pose for political systems. In search of broad agreement, policy-makers and scholars have turned to broad concepts, such as 'sustainability' or 'social inclusion' in relation to environmental and social problems. This article has probed the promises and pitfalls of these 'polysemic' ideas, supporting that they can help bring stakeholders to the table, but also showing that movement towards making effective policies can require favourable institutional conditions and specific ideas about what to do. 
Particularly at the agenda-setting stage, there are good reasons for advocates to present a united front of stakeholders and to foster cooperation between otherwise siloed sectoral interests. However, our analysis of the linkage between One Health (a polysemic concept par excellence) and AMR response (an emerging global crisis) in Australia and UK also suggests that the rallying of stakeholders around a polysemic concept is of limited value. While both countries have responded to AMR with national strategies and more specific policy initiatives, particularly in human health, Australia appears to be making less progress than the UK in critical areas such as surveillance in the veterinary health and food sectors. Moreover, Australia's primary One Health thrust appears to have been to assemble stakeholders for talks. In contrast, the UK government has assigned departmental responsibilities for AMR policy implementation, coupled with accountability targets. It is too soon to tell which country is doing better in AMR response. Instead, the analysis suggests that rather than the polysemic idea of One Health, institutions (e.g. UK centralised government v Australia's multi-level federal system) and actionable paradigms (e.g. market failure and well-understood strategies to overcome it) may be more essential factors driving AMR response.

Governments may need to impose on the interests of stakeholders or act as 'gatekeepers', narrowing the range of possible solutions and ensuring accountability. While this governance can complement deployment of polysemic concepts like One Health, the ideational emphasis on inclusiveness can mean that real politics is overlooked: sometimes losers need to be shut out to reach a political bargain. Moreover, where polysemic ideas become dominant problem and solution framing, the importance of actionable ideas may be ignored. Therefore, while malleable concepts are likely to continue to draw wide stakeholder agreement in similar cases, for meaningful and, above all, sufficient responses to be implemented, such agreement is only a beginning.

Acknowledgements Versions of this paper were presented and discussed at the 'Ideas and Crisis Response' workshop held at the University of Melbourne in December 2019 and the Public Policy Network meeting at the University of Queensland in January 2020. We are very grateful to the organisers and participants for feedback on earlier drafts.

Funding N/A.

\section{References}

Ansell, C., Boin, A., \& Keller, A. (2010). Managing transboundary crises: Identifying the building blocks of an effective response system. Journal of Contingencies and Crisis Management, 18(4), 195-207.

Australian Commission on Quality and Safety in Health Care. (2013). Report of the Australian One Health antimicrobial resistance colloquium. Sydney: Author. Retrieved from http://citeseerx.ist.psu.edu/viewd oc/download?doi=10.1.1.656.8512\&rep=rep1\&type=pdf. Accessed 6 Apr 2019.

Australian Commission on Safety and Quality in Health Care. (2017). National safety and quality health service standards. Sydney: Author. Retrieved from https://www.safetyandquality.gov.au/sites/default/ files/2019-04/National-Safety-and-Quality-Health-Service-Standards-second-edition.pdf. Accessed 6 Apr 2019.

Baekkeskov, E. (2011). Issue framing and sector character as critical parameters for government contracting-out in the UK. Public Administration, 89(4), 1489-1508.

Baekkeskov, E. (2016). Same threat, different responses: Experts steering politicians and stakeholders in 2009 H1N1 vaccination policy-making. Public Administration, 94(2), 299-315.

Baumgartner, F. R., \& Jones, B. D. (1993). Agendas and instability in American Politics. Chicago, IL: University of Chicago Press.

Béland, D., \& Cox, R. H. (2016). Ideas as coalition magnets: Coalition building, policy entrepreneurs, and power relations. Journal of European Public Policy, 23(3), 428-445. 
Béland, D., \& Howlett, M. (2015). How solutions chase problems: Instrument constituencies in the policy process. Governance, 29(3), 393-409.

Boin, A., McConnell, A., \& 't Hart, P. (2008). Governing after crisis: The politics of investigation, accountability and learning. Cambridge: Cambridge University Press.

Bresalier, M., Cassidy, A., \& Woods, A. (2015). One Health in history. In J. Zinsstag, E. Schelling, D. Waltner-Toews, M. Whittaker, \& M. Tanner (Eds.), One Health: The theory and practice of integrated health approaches (pp. 1-15). Oxfordshire: CABI.

Carstensen, M. B. (2017). Institutional bricolage in times of crisis. European Political Science Review, 9(1), $139-160$.

Carstensen, M. B., \& Matthijs, M. (2018). Of paradigms and power: British economic policy making since Thatcher. Governance, 31(3), 431-447.

Cashore, B., Bernstein, S., Humphreys, D., Visseren-Hamakers, I., \& Rietig, K. (2019). Designing stakeholder learning dialogues for effective global governance. Policy and Society, 38(1), 118-147.

Cassidy, A. (2017). One Health? Building an interdisciplinary bandwagon at the interfaces of animal health, human health and the environment. In S. Frickel, M. Albert, \& B. Prainsack (Eds.), Investigating interdisciplinary research: Theory and practice across disciplines (pp. 213-236). New Brunswick, NJ: Rutgers University Press.

Chien, Y.-J. (2013). How did international agencies perceive the avian influenza problem? The adoption and manufacture of the 'One World, One Health' framework. Sociology of Health \& Illness, 35(2), 213-226.

Davies, S. C. (2013). Annual report of the Chief Medical Officer volume two, 2011: Infections and the rise of antimicrobial resistance. London: Department of Health. Retrieved from http://media.dh.gov.uk/ network/357/files/2013/03/CMO-Annual-Report-Volume-2-20111.pdf. Accessed 27 Mar 2019.

Degeling, C., Johnson, J., Ward, M., Wilson, A., \& Gilbert, G. (2017). A delphi survey and analysis of expert perspectives on One Health in Australia. EcoHealth, 14(4), 783-792.

Department of Health. (2000). DH UK antimicrobial resistance strategy and action plan. London: Author. Retrieved from http://antibiotic-action.com/wp-content/uploads/2011/07/DH-UK-antimicrobial-resis tance-strategy-and-action-plan.pdf. Accessed 27 Mar 2019.

Department of Health. (2015). The Health and Social Care Act 2008: code of practice on the prevention and control of infections and related guidance. London: Author. Retrieved from https://assets.publi shing.service.gov.uk/government/uploads/system/uploads/attachment_data/file/449049/Code_of_pract ice_280715_acc.pdf. Accessed 27 Mar 2019.

Department of Health, \& Department of Agriculture. (2015). Responding to the threat of antimicrobial resistance: Australia's first national antimicrobial resistance strategy 2015-2019. Canberra: Author. Retrieved from https://www.amr.gov.au/file/796/download?token=Kcckyvsh. Accessed 6 Apr 2019.

Department of Health, \& Department of Agriculture. (2016). Implementation plan: Australia's first national antimicrobial resistance strategy 2015-2019. Canberra: Author. Retrieved from https://www.amr.gov. au/file/786/download?token=mBDJCrtF. Accessed 6 Apr 2019.

Department of Health, \& Department of Agriculture and Water Resources. (2017). Australia's first national antimicrobial resistance strategy 2015-2019: Progress report. Canberra: Author. Retrieved from https ://www.amr.gov.au/file/761/download?token=pW2frTWR. Accessed 6 Apr 2019.

Department of Health, \& Department of Environment, Food \& Rural Affairs. (2013). UK Five Year Antimicrobial Resistance Strategy 2013 to 2018. https://www.gov.uk/government/uploads/system/uploads/ attachment_data/file/244058/20130902_UK_5_year_AMR_strategy.pdf. Accessed 6 Apr 2019.

Duckett, S. J. (2007). The Australian health care system. Oxford: Oxford University Press.

Dunlop, C. A. (2013). Epistemic communities. In E. Araral, S. Fritzen A., M. Howlett, M. Ramesh, \& X. Wu (Eds.), Routledge handbook of public policy (pp. 229-243). Abingdon: Routledge.

Faling, M., \& Biesbroek, R. (2019). Cross-boundary policy entrepreneurship for climate-smart agriculture in Kenya. Policy Sciences, 52(4), 525-547.

Finance and Public Administration References Committee. (2013). Progress in the implementation of the recommendations of the 1999 Joint Expert Technical Advisory Committee on Antibiotic Resistance. Canberra: Australian Senate. Retrieved from https://www.aph.gov.au/ /media/wopapub/senate/commi ttee/fapa_ctte/completed_inquiries/2010-13/jetacar/report/report.ashx. Accessed 6 Apr 2019.

Food and Agriculture Organization of the United Nations, World Organisation for Animal Health, \& World Health Organization. (2018). Monitoring global progress on addressing antimicrobial resistance: Analysis report of the second round of results of AMR country self-assessment survey 2018. Geneva: Authors. Retrieved from https://apps.who.int/iris/bitstream/handle/10665/273128/9789241514422eng.pdf. Accessed 2 Apr 2019.

Gibbs, E. P. J. (2014). The evolution of One Health: A decade of progress and challenges for the future. The Veterinary Record, 174(4), 85-91. 
Haas, P. M. (1992). Introduction: Epistemic communities and international policy coordination. International Organization, 46(1), 1-35.

Haelg, L., Sewerin, S., \& Schmidt, T. S. (2019). The role of actors in the policy design process: Introducing design coalitions to explain policy output. Policy Sciences. https://doi.org/10.1007/s1107 7-019-09365-z.

Hall, P. A. (1993). Policy paradigms, social learning, and the state: The case of economic policy-making in Britain. Comparative Politics, 25(3), 275-296.

Head, B. W., \& Alford, J. (2015). Wicked problems: Implications for public policy and management. Administration \& Society, 47(6), 711-739.

Howlett, M., Mcconnell, A., \& Perl, A. (2015). Streams and stages: R econciling K ingdon and policy process theory. European Journal of Political Research, 54(3), 419-434.

Joint Expert Advisory Committee on Antibiotic Resistance. (1999). The use of antibiotics in food-producing animals: Antibiotic-resistance bacteria in animal and humans. Canberra: Author. Retrieved from https://www1.health.gov.au/internet/main/publishing.nsf/Content/health-pubs-jetacar-cnt. htm/\$FILE/jetacar.pdf. Accessed 6 Apr 2019.

Kahn, R. E., Clouser, D. F., \& Richt, J. A. (2009). Emerging infections: A tribute to the one medicine, one health concept. Zoonoses and Public Health, 56(6-7), 407-428.

Kingsley, P., \& Taylor, E. M. (2017). One Health: Competing perspectives in an emerging field. Parasitology, 144(1), 7-14.

Knaggård, A. (2015). The Multiple Streams Framework and the problem broker. European Journal of Political Research, 54(3), 450-465.

Laxminarayan, R., Malani, A., Howard, D. P., \& Smith, D. L. P. (2007). Extending the cure: Policy responses to the growing threat of antibiotic resistance. Washington, DC: Resources for the Future.

Lee, K., \& Brumme, Z. L. (2013). Operationalizing the One Health approach: The global governance challenges. Health Policy and Planning, 28(7), 778-785.

Levin, K., Cashore, B., Bernstein, S., \& Auld, G. (2012). Overcoming the tragedy of super wicked problems: Constraining our future selves to ameliorate global climate change. Policy Sciences, 45(2), $123-152$.

Mackenzie, J. S., Jeggo, M., Daszak, P., \& Richt, J. A. (Eds.). (2013). One Health: The human-animalenvironment interfaces in emerging infectious diseases: The concept and examples of a One Health approach. Berlin: Springer.

McConnell, A. (2010). Understanding policy success: Rethinking public policy. New York: Macmillan.

Nohrstedt, D. (2008). The politics of crisis policymaking: Chernobyl and Swedish nuclear energy policy. Policy Studies Journal, 36(2), 257-278.

O'Toole, L. J., \& Meier, K. J. (2004). Desperately seeking Selznick: Cooptation and the dark side of public management in networks. Public Administration Review, 64(6), 681-693.

Olson, M. (1971). The logic of collective action: Public goods and the theory of groups. Cambridge, MA: Harvard University Press.

One Health. (2017). WHO. Retrieved from http://www.who.int/features/qa/one-health/en/. Accessed 2 Apr 2019.

Parsons, C. (2015). Ideas and power: Four intersections and how to show them. Journal of European Public Policy, 23(3), 446-463.

Podolsky, S. H. (2018). The evolving response to antibiotic resistance (1945-2018). Palgrave Communications, 4, 1-8.

Public Health England. (2015). UK One Health report: Joint report on human and animal antibiotic use, sales and resistance, 2013. London: Author. Retrieved from https://assets.publishing.service.gov. uk/government/uploads/system/uploads/attachment_data/file/775075/One_Health_Report_2019_ v45.pdf. Accessed 27 Mar 2019.

Reinecke, J., \& Ansari, S. (2016). Taming wicked problems: The role of framing in the construction of corporate social responsibility. Journal of Management Studies, 53(3), 299-329.

Review on Antimicrobial Resistance. (2016). Tackling drug-resistant infections globally: Final report and recommendations. London: Author. Retrieved from https://amr-review.org/sites/default/files /160518_Final\%20paper_with\%20cover.pdf. Accessed 27 Mar 2019.

Rittel, H. W. J., \& Webber, M. M. (1973). Dilemmas in a general theory of planning. Policy Sciences, 4(2), 155-169.

Roca, I., Akova, M., Baquero, F., Carlet, J., Cavaleri, M., Coenen, S., et al. (2015). The global threat of antimicrobial resistance: Science for intervention. New Microbes and New Infections, 6, 22-29.

Sabatier, P. (1988). An advocacy coalition framework of policy change and the role of policy-oriented learning therein. Policy Sciences, 21(2-3), 129-168. 
Schmidt, V. A., \& Thatcher, M. (2013). Resilient liberalism in Europe's political economy. Cambridge, MA: Cambridge University Press.

Skogstad, G., \& Wilder, M. (2019). Strangers at the gate: The role of multidimensional ideas, policy anomalies and institutional gatekeepers in biofuel policy developments in the USA and European Union. Policy Sciences, 52(3), 343-366.

Smith, K. (2013). Beyond evidence based policy in public health: The interplay of ideas. Houndmills: Palgrave.

Termeer, C. J. A. M., Dewulf, A., Breeman, G., \& Stiller, S. J. (2015). Governance capabilities for dealing wisely with wicked problems. Administration \& Society, 47(6), 680-710.

Terms of reference. (n.d.). Review on antimicrobial resistance. Retrieved March 28, 2019, from https://amrreview.org/terms-of-reference.html.

UK AMR Strategy High Level Steering Group. (2017). UK 5 year antimicrobial resistance (AMR) strategy 2013-2018: Annual progress report, 2016. Author: London. Retrieved from https://assets.publishing .service.gov.uk/government/uploads/system/uploads/attachment_data/file/662189/UK_AMR_3rd_ annual_report.pdf. Accessed 27 Mar 2019.

UK Government. (2014). UK 5 year antimicrobial resistance (AMR) strategy 2013-2018: Annual progress report and implementation plan, 2014. London: Author. https://www.gov.uk/government/uploads/syste m/uploads/attachment_data/file/385733/UK_AMR_annual_report.pdf. Accessed 27 Mar 2019.

UK Government. (2016). Government response to the Review on Antimicrobial Resistance. London: Author. Retrieved from https://assets.publishing.service.gov.uk/government/uploads/system/uploads/attac hment_data/file/553471/Gov_response_AMR_Review.pdf. Accessed 27 Mar 2019.

UK Government. (2019). Tackling antimicrobial resistance 2019-2024: The UK's five-year national action plan. London: Author. Retrieved from https://assets.publishing.service.gov.uk/government/uploads/ system/uploads/attachment_data/file/784894/UK_AMR_5_year_national_action_plan.pdf. Accessed 27 Mar 2019.

United Nations General Assembly. (2016). Political Declaration of the high-level meeting of the General Assembly on antimicrobial resistance.

Van de Kerkhof, M. (2006). Making a difference: On the constraints of consensus building and the relevance of deliberation in stakeholder dialogues. Policy Sciences, 39(3), 279-299.

Vis, B., \& Van Kersbergen, K. (2013). Towards an open functional approach to welfare state change: Pressures, ideas, and blame avoidance. Public Administration, 91(4), 840-854.

Walsh, T. R. (2018). A one-health approach to antimicrobial resistance. Nature Microbiology, 3(8), $854-855$.

Wernli, D., Jørgensen, P. S., Morel, C. M., Carroll, S., Harbarth, S., Levrat, N., et al. (2017). Mapping global policy discourse on antimicrobial resistance. BMJ Global Health, 391, 1976-1978.

World Health Organization. (2011). World Health Day policy package to combat antimicrobial resistance. Geneva: Author. Retrieved from https://www.who.int/world-health-day/2011/presskit/WHDIntroto tobriefs.pdf. Accessed 2 Apr 2019.

World Health Organization. (2015). Global action plan on antimicrobial resistance. Geneva: Author. Retrieved from https://apps.who.int/iris/bitstream/handle/10665/193736/9789241509763_eng. pdf?sequence=1. Accessed 2 Apr 2019.

Publisher's Note Springer Nature remains neutral with regard to jurisdictional claims in published maps and institutional affiliations. 